\title{
IT Barometer Survey in Luxembourg: First results to understand IT innovation in Construction sector
}

\author{
Sylvain Kubicki ${ }^{1}$ and Conrad Boton ${ }^{1}$
}

${ }^{1}$ Public Research Centre Henri Tudor. 29 av. J.F. Kennedy. L-1855 Luxembourg; PH (352) 425991-1; email: firstname.lastname@tudor.lu

\begin{abstract}
The construction sector of Luxembourg is a particular trans-national market, where companies, methods, regulations and equipment are largely influenced by France, Germany and Belgium practices. As in other countries, IT seems to play a major role in sectorial innovation as a mean for improving competitiveness of companies and efficiency of projects delivery. There is a need for understanding the maturity of the sector regarding IT for several reasons. First the sectorial push towards innovation from public incentives and private bodies targets the areas of project management and competitiveness of companies relying on IT. Second, a nationally standardized web-based project platform (CRTI-weB) is emerging and used in several projects. However resistance is observed and is possibly caused by heterogeneous IT competencies of users. Third, BIM is gaining interest in the sector although the adoption rate remains very low. BIM seems not understood by construction practitioners as enabling new collaborative practices.

On the basis of these considerations, the paper describes the setup of the IT Barometer survey for Luxembourg. The aim of the survey conducted is to provide a robust analysis of the as-is situation of the sector regarding IT. Although the survey is still in progress, the authors provide first evidences enabling to understand the conditions in which the nationally established CRTI-weB is being adopted as well as developing requirements for the development of a BIM implementation roadmap for Luxembourg.
\end{abstract}

\section{INTRODUCTION}

The use of information technologies to describe and document interdisciplinary construction project work has been dramatically improved these last years (Fischer and Kunz 2004). According to Marsh and Flanagan (2000), to have the potential to impact industrial sectors, the information technologies have to include data transfer, data capture and data manipulation (Marsh and Flanagan 2000). But that seems not to be sufficient in AEC (architecture, engineering and construction) sector because this sector has specific processes and needs. Indeed, many studies established that the sector is mainly characterized by fragmented supply chain $(\mathrm{H}$. Howard, Levitt, Paulson, Pohl, and Tatum 1989), poor cross-disciplinary communication and poor knowledge management at industry, enterprise and project 
levels (Latham 1994; Sun and Aouad 2000) but also by many uncertainties (Tommelein 2003) and particular organizational and contractual modes (Kubicki 2006). Many other barriers exist in the application of IT in AEC sector. For example, practitioners are generally not aware about technologies and they are not sure about potential benefits (Marsh and Finch 1998). It is therefore a challenging and interesting issue to make the inventory of the use and the impact of IT in the construction industry.

This paper presents the first results of an on-going survey on the IT use in Luxembourg construction industry regarding recent innovation policies.

\section{CONSTRUCTION SECTOR AND IT INNOVATION IN LUXEMBOURG.}

CRTI-weBC, a national project management platform. In the framework of the Build-IT research project (2004-2009), the Public Research Centre Henri Tudor (http://www.tudor.lu ) was asked by CRTI-B (a professional organization) to specify and prototype a project management web-platform supporting the particular needs of Luxembourg's construction projects (Kubicki et al. 2009). CRTI-B is a public association representing most of the actors of the construction domain (Absil et al. 2008). As the prototype developed within this project proved its interest through a set of experiments (Guerriero et al. 2009), it was decided to transfer this software system to the sector as a new commercial product.

The system is commercially available since 2009. The service is provided both by CRP Henri Tudor team (marketing, training, support and evolutions management) and a software company, responsible for the IT developments. The use of CRTI-weB is mandatory required by the major public owner of Luxembourg (the Administration of Public Buildings, ABP) for the delivery of large-scale projects.

Some recurrent issues regarding IT innovation in construction. With the increasing use of CRTI-weB, some recurrent issues appeared. Among these issues, restrictions and issues related to user-access have repeatedly been reported. This issue often relates to the IT configuration and the Internet access parameters at the level of the user's company. It becomes therefore essential to understand IT practices in Luxembourg construction firms.

Another issue largely reported is related to the multiplicity of project management platforms and their impact on usages as well as on the users' requirements. CRTI-weB had been developed a few years ago with practitioners on an iterative way. Even if it was adapted to their needs, users are calling for new features which they see on other platforms and which seem useful for some of their business needs. It becomes then important to evaluate what are the other project management platforms and for which specific purpose practitioners use them for.

At the time it was created, CRTI-weB was thought to be a first step towards a better collaboration and BIM-friendly usages in Luxembourg. Today, construction firms are becoming increasingly aware of Building Information Modeling (BIM). But it is less clear how practitioners make the link between CRTI-weB and BIM. Moreover, even if practitioners are claiming to use BIM in their daily work, it is not clear if they are really implementing an actual BIM approach or if they are just using 
BIM “compliant" tools. So, before passing to a further development step where CRTI-weB would be integrated to a BIM technological environment, it is required to study which percentage of firms are using BIM and the way they implement it.

In the following sections, the paper describes a survey carried out at a national level, and based on the IT Barometer survey template. Only a part of the results is provided considering 1 ) that the survey is not fully completed at the time writing this article and 2) that the article aims to provide insights related to the issues mentioned above.

\section{IT BAROMETER SURVEY IN LUXEMBOURG.}

Development. The IT barometer survey has been created in 1997 by Olle Samuelsson from the Royal Institute of Technology of Sweden (Samuelson 2008). In its recent form, the questionnaire is organized into eight main parts.

The first part is about the company. It enables to understand the type of the company, the role of the responder in the company, and the number of employees (total, office workers, and site workers). The second part investigates the use of computers, networks and IT applications. This includes the proportion of employees with an access to this equipment, the proportion of operations that are computerized, and the practices related to IT security. The third part of the questionnaire studies the way Intranet and file servers are used at the workplace and which kind of information is managed. The fourth part deals with computer-aided design (CAD), including the design work performed and the CAD (and 3D) applications used. In fifth part, the use of project sites on Internet is investigated. This includes both the project site and what it includes in terms of information. After that, BIM (sixth part) and GIS (seventh part) practices are studied. Finally, the eighth part explores the part played by IT in the company (investment, change management, advantages, obstacles), from the respondent point of view. The standardized questions ensure that "results can be compared and that they can be repeated to gain a picture of the growth of IT use and of particular success” (Howard et al. 1998)

Related works. Surveys have been made to state the use of IT in different countries construction industries, based on IT Barometer survey. In 1998, Howard et al. presented and compare the IT Barometer survey results for Denmark, Finland and Sweden. These results showed that the use of CAD by design offices in Sweden is dominated by AutoCAD, and that architects in Denmark use more widely Microstation. Denmark is dominated by structured 2D data and Finland and Sweden firms used more CAD data structures with object.

Rivard (2000) reported "a survey on the impact of information technology on the Canadian Architecture, Engineering and Construction industry”. This survey is based on a "slightly modified and improved" version of the IT barometer survey (Rivard 2000). The results showed that all companies with computers use spreadsheets and word processors. The prevalence of the use of database systems and project planning packages was low but increasing. Bookkeeping, specifications, invoicing, technical calculations, costing and budgeting processes were largely computerized. Architects and engineers that have a computer largely used CAD 
unlike only a few contractors. Autodesk AutoCAD, MicroStation and Visio Technical were the dominant CAD software used. Moreover, most construction firms had adopted the Internet and used e-mails and the World-Wide Web on a daily basis.

Samuelson (2002) presented a second set of IT barometer surveys on Nordic construction industry (Sweden in 2000, Denmark and Finland in 2001). Compared to the 1998 surveys, word processors, administration and e-mail applications remained largely used (Samuelson 2002). Companies were slowly increasing their investments in IT. Model based CAD was more used in Finland and Denmark than in Sweden while Sweden companies prioritized costing/cost control systems.

An IT Barometer survey on Singapore construction industry was reported by Hua in 2005. The survey, largely responded by architects, showed a high percentage of use of e-mail, word processing and spreadsheet tools. But a fewer companies in Singapore had access to Internet compared to Nordic countries. Moreover, Singapore firms did not have formally documented IT strategies but used national CAD standards (Hua 2005).

Nordic countries (Sweden and Finland) were surveyed again in 2007 with the IT Barometer questionnaire and results were reported by Samuleson (2008). This time, the concept of BIM appeared in the survey and the answers. Thus, a majority of architects and less tech consultants said they were aware of BIM concept and IFC standard (Samuelson 2008). The use of "project webs" and electronic trades had also increased considerably compared to previous results.

Applied to New Zealand construction sector in 2009/2010, the IT Barometer survey revealed that project management applications were very used, after word processing, spreadsheet and e-mail applications (Davies 2010). CAD was used by a little more than half of the respondents. All architects used CAD "in some form" and many contractors did not use it at all. The use of Building Information Model (BIM) appeared clearly in the answers. But BIM was still used by some architects and a few manufacturing firms. The use of "project webs" was growing and both specific construction specific and generic file sharing systems were used. Among these tools, Aconex, Mainzeal Content Management and Sharepoint were the most cited.

More recently, the IT Barometer survey has been applied again to the Sweden construction sector (Samuelson 2012). This time, the survey showed clearly "a strong increase of awareness and use of BIM among architects" (Gustavsson and Samuelson 2012). According to Gustavson and Samuelson (2012), the rapid development of the BIM during the last five years can be explained by organizations such as buildingSMART and OpenBIM. But it is important to mention that even if BIM is more used all its functionality is not used. "Only one out of ten of the respondents claim that they work with other object-based information besides geometric data" (Gustavsson and Samuelson 2012).

Survey implementation methodology and respondents. Regarding previous studies on IT in construction, the IT barometer has always been realized in link with the first version of the survey done by Samuelson (1998). CRP Tudor conducted an amended version of the original survey for Luxembourg. Nevertheless, some specific modifications were added in order to take into consideration the Luxembourgish context. To ensure a good understanding of the cultural particularities of 
Luxembourg, the survey was translated in the most common languages practiced in the construction sector: French, German, Portuguese and English.

The data used in this paper were obtained from 150 first respondents of the Luxembourgish IT Barometer survey. The collection of the information was realized by using two different modes of collection. First, an online version was conducted. Second, a phone survey was added to be sure to capture the enterprises less comfortable with Internet. The data collection has been done during the second part of 2013 in the four languages previously identified. The response rate was of $28 \%$ by phone and less than $3 \%$ for the online part. Fifty-three per cent of the respondents are contractors or other enterprises $27 \%$ are architecture firms and $20 \%$ are engineering firms.

\section{RESULTS AND DISCUSSION}

Computers and other equipment. A very large proportion of respondents (83\%) have a computer for exclusive use, including 35\% with a laptop and 26\% with a computer at home but financed by the company (See Figure 1). They have their own e-mail address at the company (76\%) but not own e-mail address by projects (only 6\%). A majority of firms (53\%) provide mobile phone at their employees' disposal. Smartphones, tablets and other mobile devices with internet connection are provided to employees by 32\% of firm. Eighty-four per cent of people in construction firms have Internet access from their own computer.

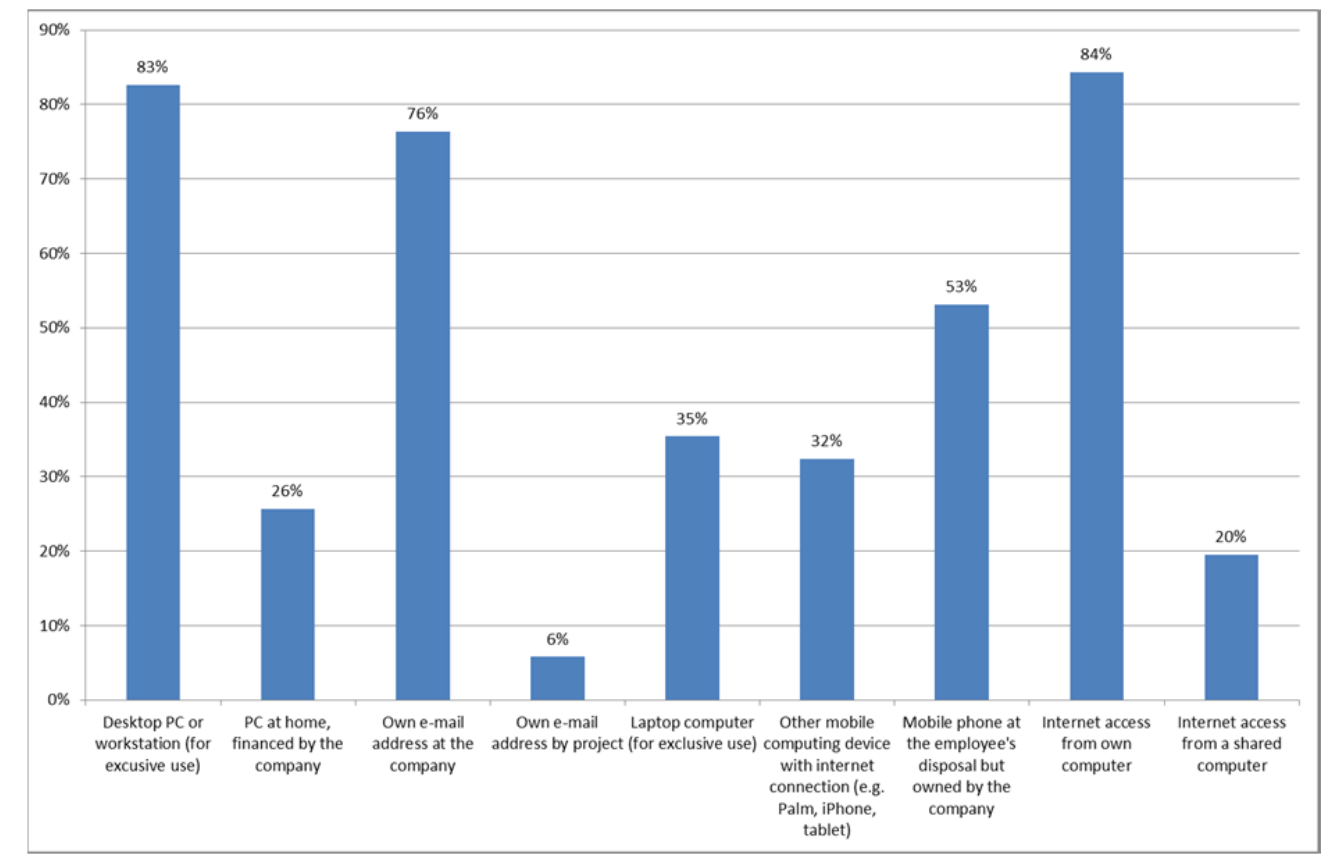

Figure 1. Computers and other equipment

Among the projects management platforms used, respondents mention CRTIweB, Endex, Dropbox, Bentley Projectwise and Google Drive. Forty-for per cent of the respondents use fileservers. Figure 2 shows the type of information the fileservers deal with. The large majority of them contain project information, project drawings, personal information, project reports, quality information and project contracts. 
CRTI-weB provides services for project information, project drawings and project reports. Personal and quality information are not covered yet. Manuals, photos and news are also usually contained in companies' filerservers. Besides the mobile version of CRTI-weB current under development, a prototype of mobile system to manage construction site information using photos had been developed (Macarulla et al. 2012).

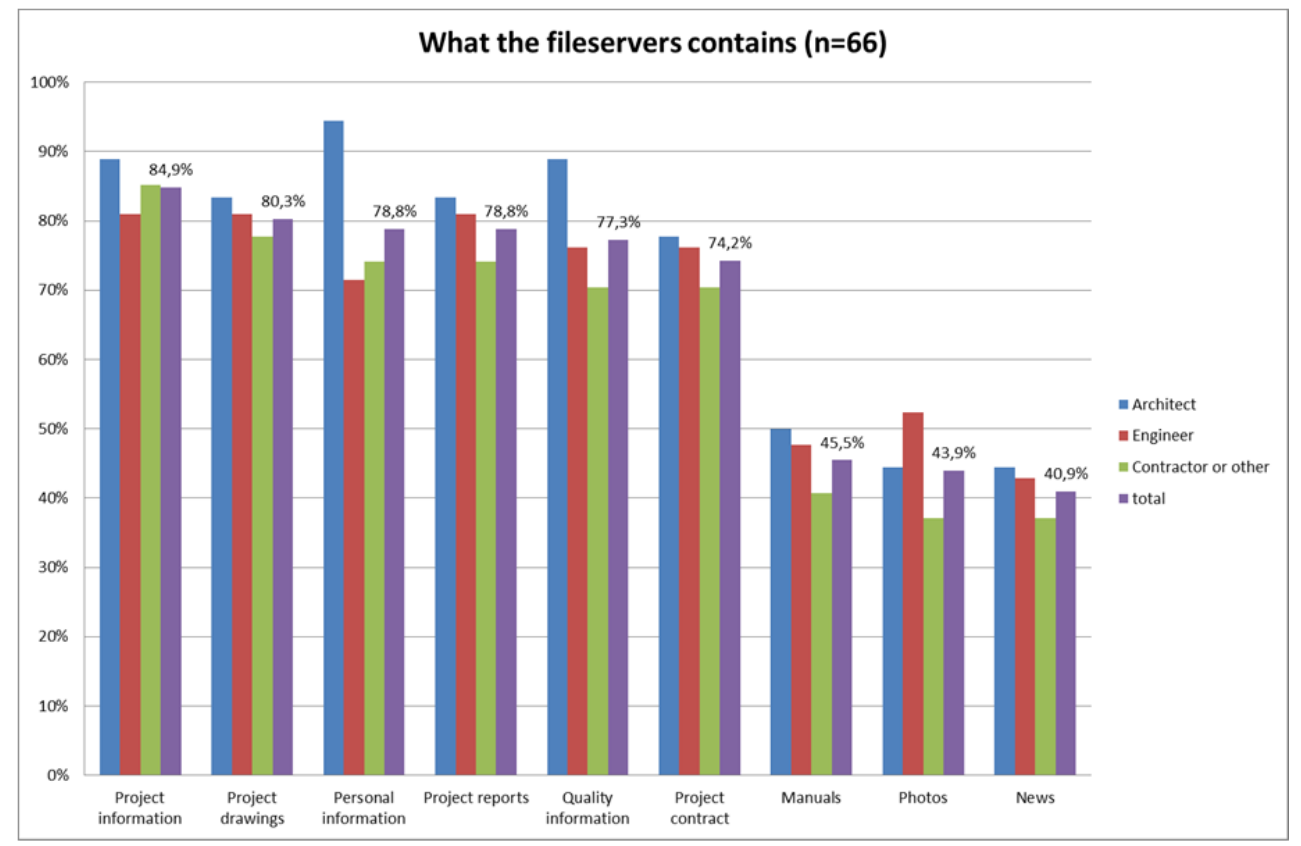

Figure 2. What do the fileservers contain?

BIM awareness. The firms are not very familiar with BIM yet, especially engineers and contractors. Indeed, even if architects are more familiar since almost $40 \%$ of them claims they are so, only $6.9 \%$ of engineers and $9 \%$ of contractors seem aware of BIM. Curiously, more than $30 \%$ of engineers and $29 \%$ of contractors claim that they are familiar with the IFC standard. This is probably due to the fact that IFC is perceived as a file format they deal with in their CAD software, and not as part of a BIM approach.

Practitioners are also unfamiliar with 4D modeling. Indeed, $77.5 \%$ of architects, $90 \%$ of engineers and $88.6 \%$ of contractors are not familiar with it. Building products catalogs are more known in the construction firms, mainly by architects (60\%) and less by engineers (33.3\%) and contractors (29.2\%). 


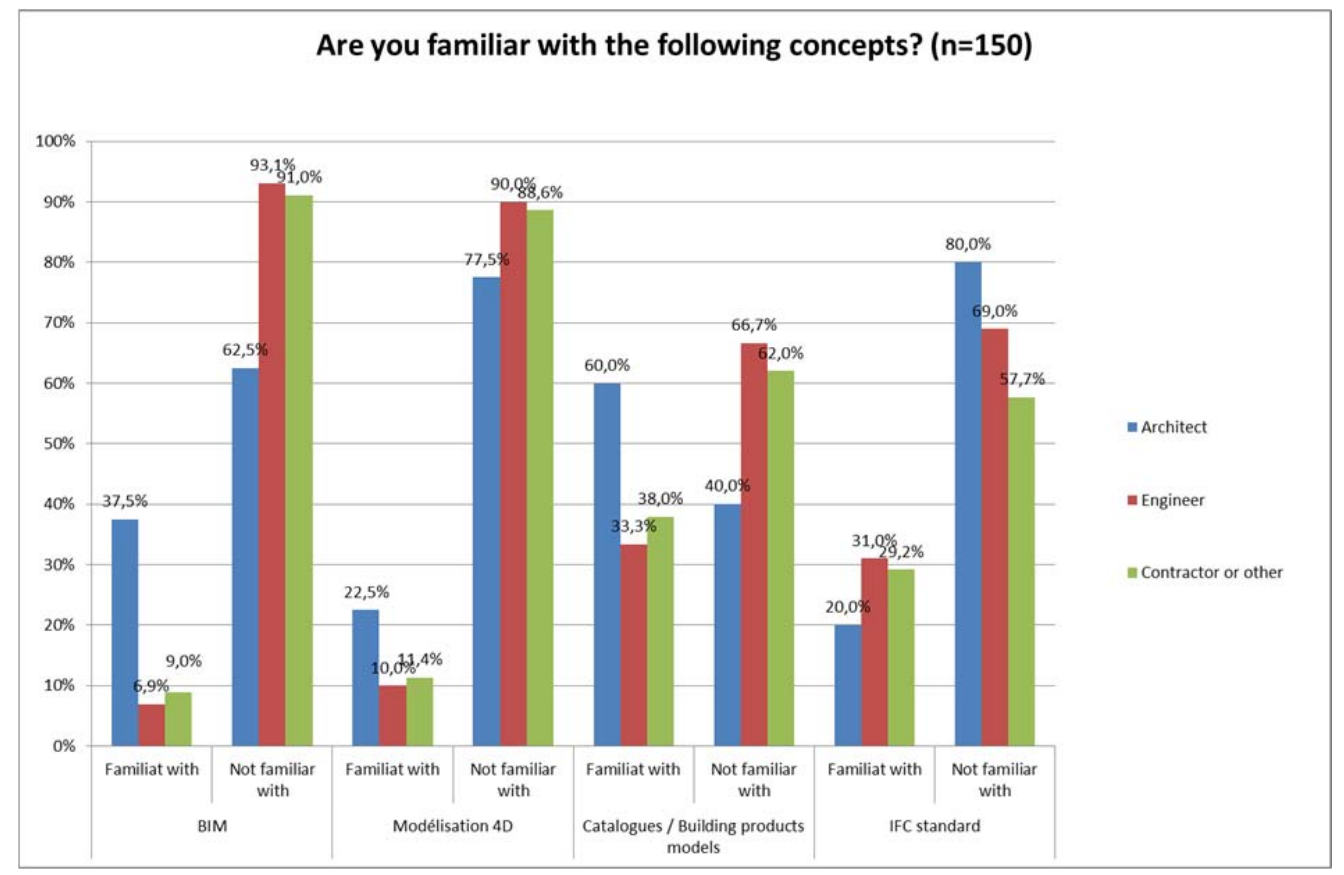

Figure 3. Building Information Modeling awareness

\section{CONCLUSION}

This paper addresses some recurrent issues observed in the framework of our public innovation activities for the construction sector in Luxembourg. In particular, it provides insights to questions related to the use of web-based project management platforms and to the implementation of BIM-based processes in Luxembourg's construction projects.

Beyond other lessons, we first retain that a very large proportion of respondents have access to their own computer as well as to an Internet connection. Secondly, CRTI-weB appears to be the most used project management tool in the Luxembourg construction sector (at least from our 150 first respondents).

Compared to recent IT Barometer results (e.g. New-Zealand and Sweden), the growing use of project management applications is also observed in Luxembourg. However the familiarity of practitioners with BIM approach is lower. It is important to notice that IT Barometer is not the most accurate questionnaire to study BIM practices. For this reason, another survey is planned using a recognized BIMdedicated questionnaire. Such a survey will focus on model-based collaborative modeling practices in order to study the BIM maturity of the Luxembourg construction industry.

For now, the current IT Barometer survey is still ongoing during the first months of 2014, and paper-based questionnaires have also been sent in order to obtain responses from very small architectural offices and contractors. Once the dataset will be robust enough, wider and detailed results will be published.

\section{ACKNOWLEDGMENT}

The authors thank NeoBuild, the innovation cluster for sustainable construction in Luxembourg, for supporting this activity as part of their "animation" mission. 


\section{REFERENCES}

Absil, F., Dubois, E., Grein, L., Michel, J.-P., and Rousseau, A. (2008). Trust in the Heart of the Open Innovation: Lessons by the Resource Centre for Information Technologies for the Building Industry. International Society for Professional Innovation Management (ISPIM).

Davies, K. (2010). IT Barometer New Zealand-A survey of computer use and attitudes in the New Zealand construction industry. In Conference on Applications of IT in the AEC Industry CIB 2010. Cairo, Egypt.

Dubois, E., and Rousseau, A. (2013). Service Science: A Service System Design Science Research Method? In Exploring Services Science (pp. 100-113). Springer.

Guerriero, A., Johannsen, L., and Kubicki, S. (2009). Designing IT services for the Construction Industry. Lessons learnt for Selection of Validation Techniques. In Proceedings of 26th International Conference CIB-W78. Managing IT in Construction (p. 10 p.). Istanbul, Turkey.

Gustavsson, T. K., and Samuelson, O. (2012). Organizing it in construction: Present state and future challenges in Sweden. ITcon Electronic Journal of Information Technology in Construction, 17(March), 520-533.

Howard, R., Kiviniemi, A., and Samuelson, O. (1998). Surveys of IT in the construction industry and experience of the IT barometer in Scandinavia, 3(November), 45-56.

Hua, G. B. (2005). IT barometer 2003: Survey of the Singapore construction industry and a comparison of results. Development, 10(December 2004), 1-13.

Kubicki, S., Guerriero, A., and Johannsen, L. (2009). A service-based innovation process for improving cooperative practices in AEC. Journal of Information Technology, 14(October), 654-673.

Macarulla, M., Forcada, N., Casals, M. and Kubicki, S. (2012). Tracking construction defects based on images. European Conference on Product and Process Modelling, ECPPM 2012. Reykjavik, Island. July 25-27, 2012. CRC Press 2012. 723-729.

Rivard, H. (2000). A survey on the impact of information technology on the Canadian architecture, engineering and construction industry. Electronic Journal of Information Technology in Construction, 5(February), 37-56.

Samuelson, O. (2002). IT-Barometer 2000 - The use of IT in the Nordic construction industry. ITcon Electronic Journal of Information Technology in Construction, 7(January), 1-26.

Samuelson, O. (2008). The IT-Barometer-A decade's development of IT use in the Swedish construction sector. ITcon, 13(December 2007), 1-19.

Samuelson, O. (2012). IT-Barometern 2011: En mätning av bygg-och fastighetssektorns IT-användning. 